\title{
Ocupación social del espacio en el Estado de Tlaxcala, México, 1980-2017
}

Social Occupation of the space in the State of Tlaxcala, Mexico, 1980-2017

María Concepción Martínez, Rolando Reynoso Pérez, Miguel Alvarado Carbona y Javier Romero *

Fecha de envío: 12 de agosto de 2017

Fecha de aceptación: 22 de noviembre de 2017

\section{Resumen}

Actualmente, el estado de Tlaxcala enfrenta grandes desafíos en materia de ordenamiento territorial y gestión urbana, pues desde el último tercio del siglo pasado ha experimentado un rápido incremento demográfico en las localidades rurales que conforman a la periferia de sus ciudades, lo que se traduce en una rápida urbanización del estado, pero también en grandes retos para afrontar esta transición demográfica.

Este estudio pretende explicar el proceso de urbanización de la zona metropolitana del estado entre 1980 y 2017, utilizando la información estadística disponible y fundamentándose en diversas teorías de desarrollo urbano, con el objetivo de realizar una caracterización del sistema territorial con la información existente, e incorporar el análisis de las diferentes interacciones de los sistemas naturales, sociales, económicos y jurídicos que influyen en la dinámica poblacional de Tlaxcala, para posteriormente, hacer un diagnóstico del estado e identificar las principales debilidades del modelo de desarrollo urbano actual. Finalmente, se realiza una propuesta para orientar el ordenamiento territorial del estado, que aterrice en las necesidades concretas de infraestructura, servicios y estrategias de desarrollo requeridas para lograr una integración eficiente, ordenada y sustentable de las localidades rurales a la región metropolitana de Tlaxcala.

Palabras clave: ocupación social, crecimiento demográfico; desarrollo urbano; ordenamiento territorial.

\begin{abstract}
Currently, the state of Tlaxcala faces major challenges in terms of territorial planning and urban management. Since the last third of the last century, it has experienced a rapid population increase in the rural towns that make up the periphery of their cities, which translates into a rapid urbanization of the state, but also great challenges to face this demographic transition.

This study aims to explain the process of urbanization of the metropolitan area of the state between 1980 and 2017 using the available statistical information and based on various theories of urban development, with the aim of carrying out a characterization of the territorial system with the existing information, and incorporate the analysis of the different interactions of the natural, social, economic and legal systems that influence the population dynamics of Tlaxcala, to subsequently make a diagnosis of the state and identify the main weaknesses of the current urban development model. Finally, a proposal is made to orient the territorial ordering of the state, which lands in the specific needs of infrastructure, services and development strategies required to achieve an efficient, orderly and sustainable integration of the rural localities to the metropolitan region of Tlaxcala.
\end{abstract}

Keywords: social occupation, population growth, urban development, territorial planning.

\footnotetext{
* Filiación: Instituto Politécnico Nacional, México. Correo electrónico: mconcepcionmr@yahoo.com.mx
}

Cómo citar: Martínez, M., Reynoso, R., Alvarado, M. y Romero, J. (2017). Ocupación social del espacio en el Estado de Tlaxcala, México, 1980-2017. Revista de Urbanismo, 37, 1-17. https://doi.org/10.5354/0717-5051.2017.47061 


\section{Introducción}

La dinámica de urbanización en México y los países latinoamericanos ha sido influenciada directamente por el proceso de globalización, lo cual, en las últimas décadas se ha visto reflejado en el acelerado crecimiento demográfico y la rápida transición de regiones rurales a urbanas, lo que sitúa al ordenamiento territorial y la gestión urbana como un amplio tema de debate, reflexión y análisis (Gutiérrez, 2013).

En el presente trabajo se estudia el proceso de urbanización, desde el enfoque de la ocupación social del espacio en la Región Metropolitana del estado de Tlaxcala, al ser el cuarto estado de México con mayor densidad poblacional y uno de los estados de la Región Centro de México, conformada por la Ciudad de México, el Estado de México, Morelos, Hidalgo, Puebla, Tlaxcala y Querétaro, por lo anterior y aunado a la falta de planeación integral y a la inadecuada ejecución de los proyectos de ordenamiento territorial, Tlaxcala presenta problemas de desarrollo urbano y territorial. Este tipo de expansión urbana con poca o nula planeación, eventualmente genera degradación ambiental, desarticulación funcional urbana entre localidades periféricas a las ciudades, irracionalidad de usos del suelo, dispersión e insuficiencia de servicios e infraestructura, y en general una masa humana desintegrada que genera diversos problemas sociales que, a su vez, dificulta establecer un adecuado ordenamiento territorial. (Bazant, 2001).

Para realizar el diagnóstico del sistema territorial, la investigación se basó en los siguientes elementos teórico-metodológicos y conceptuales:

- La ocupación social del espacio (Reynoso et al., 2012)

- El proceso de urbanización trabajado en el contexto del desarrollo regional contemporáneo, que comprende entre otros, a elementos, conceptos y categorías de la idiosincrasia cultural de las comunidades tlaxcaltecas, (Sobrino, 2012)

- Las relaciones sociales de producción (Lattuada, 2002)

- De la formación y crecimiento de los asentamientos humanos existentes en la región expresados como la relación de un complejo sistema de centros de población y a su vez, como un sistema de localidades y ciudades, correlacionadas entre sí, que le dan forma, materia y contenido (Hernández, 2008; Aguilar, 2004) a las estructuras territoriales a la urbanización capitalista (Harvey, 2007)

- La teoría del desarrollo-subdesarrollo (Ramírez, 2008)

- En tanto teoría de la dependencia a través de centrosperiferias y de otros elementos más en la materia (Guillén, 2004)

En el mismo sentido es que el sociólogo Maya (1987) reflexiona acerca de la ocupación social del espacio en cuanto a que:

La ocupación social del espacio, en el contexto histórico ambiental, significa una manera de entender el análisis que tenga en cuenta la relación de la sociedad con los sistemas físico-bióticos que la sustentan. Lo ambiental es, en consecuencia, "un espacio", al mismo tiempo óntico y epistemológico, en donde confluyen lo "social" y lo "natural" y, por tanto, las ciencias sociales y naturales. Un espacio óntico, es decir, "un espacio de la realidad natural" modificada por la actividad social, y "un espacio epistemológico" que exige la influencia de las diferentes disciplinas para comprender las determinaciones correspondientes biunívocas entre la relación que existe de lo natural y lo social. El problema ambiental es una crisis del sistema natural en su conjunto, que se debe a la modalidad específica de adaptación instrumental en la que se concluye la evolución biológica. No es, sino la crisis de la especie humana en sus formas de adaptación al medio (Maya, 1987).

Algunos autores, consideran que el enfoque territorialista implica una visión multidisciplinar y transdisciplinar, para que sea capaz de afrontar los complejos desafíos de las dinámicas territoriales. Otros estudios sobre el ordenamiento territorial y el análisis espacial conceptúan acerca de lo que es el espacio en sí (semántica y tiempo) y el espacio diferenciado (semiótica y contenido de relaciones sociales y económicas). Por lo que cabe hacer la pregunta: ¿Qué es el espacio? Lipietz, cataloga como empirista a la concepción epistemológica del espacio desde las perspectivas geográfica y económica. Argumentando que, para los geógrafos, lo real se divide en segmentos o regiones delimitadas 
espacialmente, inmediatamente identificables, cuyo único objeto es la detallada descripción, pudiendo ser arbitraria en la identificación del contenido real del espacio al limitarse a la cuantificación de datos. A su vez, aborda que el espacio en términos económicos es un espacio abstracto, matemático e igualmente empirista, siendo tan solo un receptáculo de los hombres y sus actividades. Esta ruptura de la concepción empirista del espacio busca aceptar que toda realidad y relación social, tienen formas de existencia material y temporal, así, esta estructura específica de la realidad social, posee niveles que no se desarrollan en el mismo período histórico, por lo que debería de asignárseles un tiempo propio autónomo aunque no totalmente independiente (Peñalver, 2000).

Por su parte, Bachelard, opina que no hay progreso con la "geografía cuantitativa anglosajona", empeñada en cuantificar la descripción y olvidando "reflexionar para medir y no medir para reflexionar".

La posición de los economistas es cuando dicen que es un continente en el que se inscriben objetos. Los teóricos de la "economía espacial" o regional, "aprehenden" la dimensión espacial de los problemas económicos de dos maneras:

a) Partiendo de las teorías económicas generales y desmenuzando sus objetos en sub objetos regionales.

b) Considerando el espacio euclidiano en dos dimensiones: "superficie" que se consume, pero no se produce, es la óptica de la formación de la teoría de la renta en economía espacial.

En el caso de las teorías del primer caso, la delimitación del espacio económico es algo "dado" y cada país, ciudad o región, se reduce entonces a una "personalidad" empíricamente medible. En el segundo caso, la delimitación no está dada, y la teoría intenta explicarla.

Así, se sigue con un esquema de circulación de teorías y conceptos urbanos, mientras se encuentra que, la fase actual del capitalismo está afectando no sólo las esferas económicas sino también la urbana, encontrando a menudo choques entre lo local y lo global (Navarrete, 2013), así, esta fase constituye la expresión de una sociedad organizada según un modelo organizado en base a nodos y redes (de Mattos. 2002).
Dado el análisis anterior y tomando en consideración el primer caso, este trabajo se ha definido para estudiar la forma de ocupación social del espacio en el estado, analizando las interacciones de las localidades rurales con los centros urbanos de la zona urbana del estado, a través del proceso de urbanización contemporáneo vigente en la región, apoyándose en el análisis de la población en sí, la vivienda cuantificable y el uso del suelo urbano; como los principales ejes rectores de los elementos que se estructuran como una totalidad en movimiento continuo y que se despliega según los determinados contextos históricos y ámbitos situados que permanentemente reconfiguran al territorio y a los sistemas naturales, sociales y económicos.

Así pues, esta investigación tiene por objetivo analizar el actual proceso de urbanización capitalista y determinar cómo ha direccionado las diferentes formas de ocupación social del territorio del estado de Tlaxcala, y con ello, ofrecer una visión integral del modelo de desarrollo del estado y sus instrumentos de ordenamiento territorial, para finalmente, realizar propuestas concretas que atiendan las debilidades del actual modelo de desarrollo a corto, mediano y largo plazo.

Antecedentes del Marco Jurídico y del Ordenamiento Territorial en Tlaxcala

Desafortunadamente, la normatividad mexicana en materia de desarrollo urbano y ordenamiento territorial ha manifestado problemas, incongruencias y contradicciones debidas a la falta de incorporación de las características determinantes de la expansión de las ciudades en la legislación y planes de desarrollo urbano, así como la desarticulación entre normatividad y planes con las acciones de los sectores populares e inmobiliario además de la falta de capacidad técnica y política para enfrentar razonablemente las funciones urbanas (Garza, 2007). Por lo cual, a continuación, se hará una revisión de los instrumentos del ordenamiento territorial en Tlaxcala, pues es necesario establecer la relación del ordenamiento territorial y el marco jurídico existente, al plantear dos cuestiones importantes de análisis: si el objeto del ordenamiento del territorio es un ámbito concreto de la intervención pública, y saber si ese objeto de intervención pública y regulación jurídica está asociado a un derecho y a instituciones jurídicoadministrativas específicas (Ugalde, 2010), puesto que, con frecuencia es reconocida la ausencia o debilidad de los planteamientos teóricos que respaldan la toma de 
decisiones por parte de los actores que definen la conformación de las ciudades en México (Quiroz, 2013).

Debido a las elevadas exigencias normativas y a la falta de mecanismos de acceso al suelo durante el siglo pasado en algunos países latinoamericanos, entre ellos México, una gran parte de la población resolvió sus necesidades habitacionales por fuera de los mecanismos del mercado inmobiliario formal, lo cual conllevó a un desarrollo irregular y desordenado de las ciudades, así, las políticas de regularización territorial urbanoambiental surgieron en la década de 1960 (Di Virgilio, 2014).

En México, se hizo manifiesta la preocupación por los efectos del proceso acelerado de urbanización desde la década de 1970, lo cual resultó en la generación de iniciativas para sentar las bases jurídicas por parte del Estado, para establecer las pautas de intervención, lo que se concretaría con la expedición de diversos ordenamientos y la creación de diferentes instancias vinculadas con el desarrollo urbano (Gutiérrez, 2017).

A pesar de esto, no fue hasta el año 2004 que Tlaxcala aborda el tema desde una perspectiva de gestión regional del territorio con el Programa de Ordenamiento Territorial del Estado de Tlaxcala 2004, el cual estableció una regionalización con base a las características de funcionalidad vial, de tipo natural, económico y social, concentradas en los municipios del estado, dicha regionalización dividió al estado en las seis regiones con su respectiva cabecera regional, mostradas en la figura 1: Región Norte (Tlaxco), Oriente (Huamantla), Poniente (Calpulalpan), Centro-Norte (Apizaco), Centro-Sur (Tlaxcala) y Sur (Zacatelco).

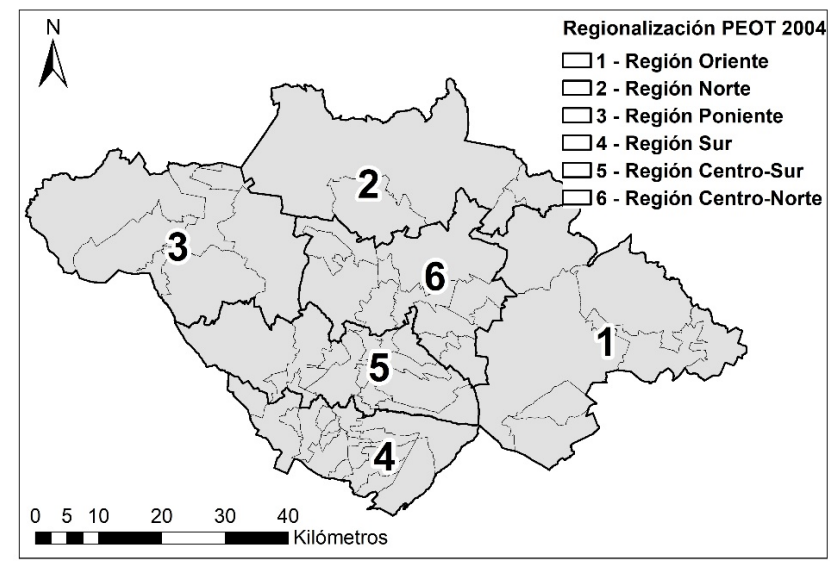

Figura 1. Regionalización del estado de Tlaxcala, PEOT 2004.

Fuente: Elaboración propia con información del Marco Geoestadístico Nacional 2017 (INEGI, 2017b).
Sin embargo, dicha regionalización, correspondía a la realidad y contexto de Tlaxcala en la década de 1990 y la primera década del siglo XXI, hasta ese momento, el estado había presentado un proceso de urbanización ideal, estableciendo tierras agrícolas en la periferia de las localidades. Pero en las últimas décadas, este comportamiento se modificó, caracterizándose por un crecimiento irregular y a la deriva, la población rural se distribuye a lo largo del Estado en sus 1,382 localidades, expandiendo la mancha urbana de una manera desordenada, en ocasiones generando deterioro ambiental y la disminución de la calidad de vida de los habitantes de esta zona, haciendo obsoleta la regionalización del Programa de Ordenamiento Territorial de Tlaxcala de 2004.

Por lo que en el Programa de Ordenamiento Territorial y Desarrollo Urbano de Tlaxcala 2013 (POTDUT) se realizó una propuesta de regionalización que corresponde a la reconfiguración demográfica del estado en el siglo $\mathrm{XXI}$, dividiendo al municipio en tres regiones finales, la región 1 Centro-sur (Apizaco-TlaxcalaZacatelco) con 41 municipios, la región 2 (Huamantla) con 9 municipios y la región 3 Norponiente (CalpulalpanTlaxco) con 10 municipios (Figura 2).

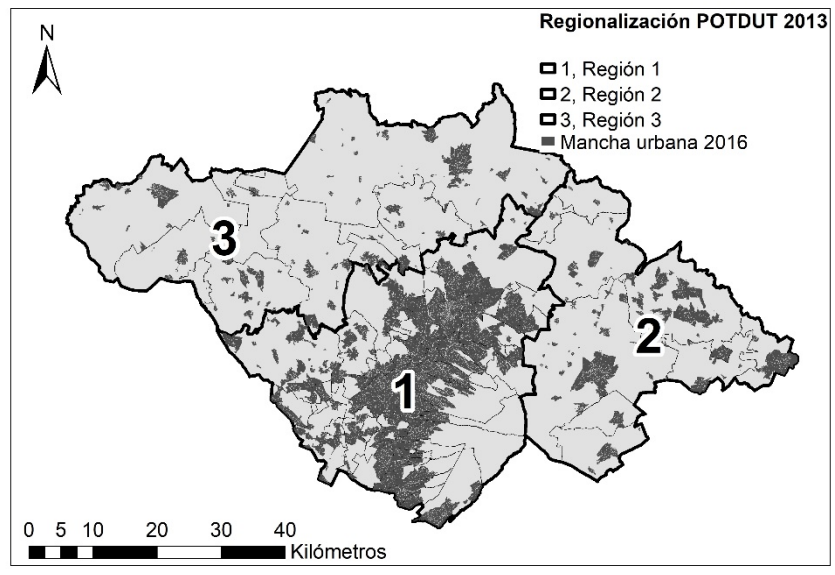

Figura 2. Propuesta de Regionalización del estado de Tlaxcala, POTDUT 2013.

Fuente: Elaboración propia con información del Marco Geoestadístico Nacional 2017 (INEGI, 2017b). 
A pesar de la congruencia de la propuesta, encaminada a mejorar la gestión territorial del estado, hasta el momento no se ha generalizado esta regionalización para el desarrollo de los Planes de Desarrollo Municipal ni de los Programas Municipales de Ordenamiento Territorial.
Actualmente, solo cuatro de las seis cabeceras municipales cuentan con un Programa Municipal de Desarrollo Urbano (Huamantla, Tlaxcala, Apizaco y Zacatelco) mientras que todos los municipios cabecera cuentan con un Plan Municipal de Desarrollo, excepto Zacatelco. Hoy, el estado de Tlaxcala cuenta con los Ordenamientos Territoriales mostrados en la tabla 1.

Tabla 1. Ordenamientos Territoriales Vigentes en el Estado y Municipios de Tlaxcala.

\begin{tabular}{|c|c|c|}
\hline Título & Tipo de Ordenamiento & Fecha de Publicación \\
\hline Ley de Ordenamiento Territorial para el Estado de Tlaxcala & Ley & $03-12-2004$ \\
\hline Programa de Ordenamiento Territorial y Desarrollo Urbano para el Estado de Tlaxcala & Programa & 04-06-2013 \\
\hline Reglamento de Ordenamiento Territorial e Imagen Urbana & Reglamento & 05-06-2013 \\
\hline \multicolumn{3}{|c|}{ Programas Municipales de Desarrollo Urbano } \\
\hline Programa Municipal de Desarrollo Urbano de Huamantla & Programa & 24-09-2014 \\
\hline Programa Municipal de Desarrollo Urbano de Zacatelco & Programa & $16-11-2016$ \\
\hline \multicolumn{3}{|c|}{ Planes Municipales de Desarrollo } \\
\hline Plan Municipal de Desarrollo 2011-203, Tlaxcala & Plan & $16-05-2011$ \\
\hline Plan de Desarrollo Municipal 2014-2016, Tlaxco & Plan & 06-08-2014 \\
\hline Plan Municipal de Desarrollo H. Ayuntamiento de Huamantla, 2014-2016 & Plan & $30-04-2014$ \\
\hline
\end{tabular}

Fuente: Elaboración propia con información de la Secretaría de Gobernación (SEGOB, 2017 en línea: http://www.ordenjuridico.gob.mx/)

\section{Metodología}

Para realizar el estudio de la ocupación social en el Estado de Tlaxcala, la investigación consistió en dos pilares fundamentales, un análisis del crecimiento urbano y un análisis espacial de las regiones de mayor crecimiento en el Estado.

Para que el estudio alcance el objetivo planteado, se estructuró con anterioridad al desarrollo de este trabajo y de acuerdo con el grupo, llevar a cabo una secuencia metodológica compuesta por tres contenidos principales a saber:

1. La primera etapa, consistió en el acopio de información del marco jurídico, información histórica y estadística, así como información tanto de campo como de gabinete y de otros sectores, dependencias u organismos.

2. Posteriormente, la segunda etapa consistió en realizar una caracterización de los principales y más destacables entes urbanos y elementos de la zona con los datos obtenidos en la etapa de recopilación documental
3. Para que finalmente, después de su respectivo análisis se generase el diagnóstico de la misma, y con ello las propuestas para atender las debilidades halladas.

Dado lo anterior, en un primer avance se recopiló la mayor información bibliográfica especializada en la materia, así como los documentos; a su vez, se obtuvieron los principales documentos cartográficos para la zona; entre ellos, el Marco Geoestadístico Municipal de los Conteos de Población y Vivienda de los años 1995, 2000 y 2005, así como la Cartografía Geoestadística Urbana y Rural Amenazada, Junio 2016, y el Marco Geoestadístico Nacional, Junio 2017, de los cuales se emplearon las áreas geoestadísticas con tres niveles de desagregación: Estatal (AGEE), Municipal (AGEM) y Básica (AGEB) tanto rurales, es decir, localidades con 2,499 habitantes o menos, como localidades urbanas con 2,500 habitantes y más, de acuerdo a los criterios para México, del Instituto Nacional de Estadística y Geografía. Asimismo, se localizaron otras cartas temáticas, como las 
Cartografía de Uso del Suelo y Vegetación Series IV y V; además de fotografías aéreas de escala 1: 50,000 e imágenes espaciomapa con escala de 1: 50,000.

En el mismo sentido se llevaron a cabo comunicaciones con diferentes organismos, oficinas $y$ dependencias, tanto académicas como del sector privado y otras, tanto en el estado de Tlaxcala como en la Ciudad de México; algunas de ellas como la Secretaría de Desarrollo Urbano, Vivienda y Ecología (SDUVET) del Gobierno del Estado; representaciones delegacionales en el estado como la Secretaría de Medio Ambiente y Recursos Naturales (SEMARNAT); en el mismo orden, se acudió a las oficinas de la Presidencia Municipal de los principales municipios mencionados anteriormente; también se contactó al Instituto Nacional de Estadística, Geografía e Informática (INEGI); al Consejo Nacional de Población (CONAPO); a la Comisión Nacional del Agua (CNA) y otros organismos importantes que tenían que ver con este estudio.

Posteriormente con los materiales conseguidos como la bibliografía, fotografías tomadas en los recorridos para verificación en campo y la ciudad, cartografía, fotos aéreas adquiridas y el espacio mapa, aunado a entrevistas con habitantes de las localidades por los municipios involucrados y principalmente por aquellos con límites de los municipios colindantes, se procedió a delimitar el área de estudio, la cual abarcó a los 44 municipios pertenecientes a las tres zonas metropolitanas de la entidad; Tlaxcala - Apizaco, Puebla - Tlaxcala y la emergente Zona Oriente, Huamantla - El Carmen Tequexquitla.

Además, se analizaron los materiales de información conseguidos, entre los que destacan, los instrumentos jurídicos de los tres niveles de gobierno que se vinculan con el Ordenamiento Territorial (véase tabla 2.) los Programas Municipales de Desarrollo Urbano y los Planes de Desarrollo Municipal de las cabeceras regionales del Estado (tabla 1.), la adquisición de algunos libros y otros de importancia; todo ello con el fin de contar con los datos de los elementos necesarios para realizar la caracterización y el diagnóstico de los principales elementos tanto del medio social y como del medio económico de la zona; como son entre otros: población total, población urbana y población rural; vivienda, servicios y dinámica poblacional; planes, programas y política de gobierno, desarrollo urbano, procesos de urbanización e inversiones en la materia, población económicamente activa de acuerdo a los sectores económicos de la producción; población económicamente inactiva, empleo y desempleo; salarios, producto interno bruto e ingreso per cápita.

Tabla 2. Estructura normativa Vinculada con el Desarrollo Urbano y Ordenamiento Territorial en el estado de Tlaxcala

\section{Leyes Federales}

- Constitución Política de los Estados Unidos Mexicanos

- Ley General de Asentamientos Humanos

- Ley General del Equilibrio Ecológico y la Protección al Ambiente

- Ley de Planeación

- Ley Agraria

- Ley de Desarrollo Rural Sustentable

- Ley General de Población

- Ley Federal de Vivienda

- Ley General de Bienes Nacionales

- Ley de Adquisiciones y Obras Públicas

- Ley Federal sobre Monumentos y Zonas Arqueológicos, Artísticos e Históricos

- Ley Federal de Responsabilidad Ambiental

\section{Leyes Estatales}

- Ley de Ordenamiento Territorial para el Estado de Tlaxcala

- Ley Municipal para el Estado de Tlaxcala

- Ley de Aguas del Estado de Tlaxcala

- Ley de Comunicaciones y Transportes

- Ley de Desarrollo Forestal Sustentable para el Estado de Tlaxcala

- Ley de Fomento Económico del Estado de Tlaxcala

- Ley de Patrimonio Público del Estado de Tlaxcala

- Ley de Turismo para el Estado de Tlaxcala

- Ley de Vivienda del Estado de Tlaxcala

Fuente: Varias, complementada con información de la Normateca del Estado de Tlaxcala.

Entre los indicadores utilizados para hacer un análisis de la evolución de la sociedad tlaxcalteca, se utilizó el porcentaje de grado de urbanización, al ser un indicador del nivel que un centro urbano tiene en cuanto a su capacidad para proporcionar una serie de servicios a un área más extensa (Hernández, 2008).

En cuanto a la vivienda, se utilizaron los datos contenidos en los respectivos censos generales de población y vivienda, de 1980 al 2010, así como los conteos de población 2005 y 2015 (INEGI, 2005, 2015). 
Aunado a los recorridos de verificación de campo en donde se constataron las características de las viviendas y sus mínimos servicios esenciales. El indicador de viviendas por hectárea varía de acuerdo con cada zona y de lo mínimo establecido de 3 viviendas por hectárea a máximos económicos del capital inmobiliario. De tal forma que el crecimiento de la población conlleva la necesidad de contar con viviendas dignas y espacios urbanos adecuados, con el fin de llevar a cabo el mejor desarrollo de las cuatro funciones principales de las actividades humanas, como lo es: habitar, circular, trabajar y recrear (Le Corbusier, 1990) y en consecuencia surge la necesidad de contar con elementos de equipamiento como bienes, obras y servicios.

El indicador de carácter urbano "porcentaje de población ocupada en actividades no agrícolas" también se calculó con base en el XII Censo General de Población y Vivienda 2000, omitiendo del denominador a la población ocupada que no especificó su sector de actividad económica; mientras que la densidad media urbana de los municipios se obtuvo a partir de la densidad bruta (población entre superficie) de cada una de sus áreas geoestadísticas bases urbanas ponderadas por el tamaño de su población.

La distancia por carretera a la ciudad principal fue el único indicador que se estimó en forma selectiva. Ésta se calculó sólo para aquellos municipios que no fueron definidos como centrales pero que cumplen con los criterios de integración funcional y carácter urbano señalados anteriormente, así como para aquellos municipios que están reconocidos como parte de una zona metropolitana. Para su medición se utilizaron los polígonos de las localidades urbanas de la cartografía Conteo de Población y Vivienda 2005, en combinación con la información de carreteras de la Carta Topográfica escala 1:250 000, en formato digital.

En la siguiente etapa se describieron las características de los elementos poblacionales y de los anteriormente mencionados, utilizando la información de los datos encontrados por décadas que viene en los censos generales de población y vivienda de 1980 al 2010; y para los datos del 2005 y 2015, en los rubros correspondientes se utilizaron los anuarios estadísticos del estado de Tlaxcala (INEGI, 2005, 2017a).

En la tercera y última etapa de este apartado, se pretendió hacer un enfoque general de la evolución del sistema de las ciudades en mención como parte de un todo que es el sistema de centros de población, el cual se entiende como el conjunto de asentamientos humanos de cualquier tipo y tamaño, por lo que en él se encuentran incluidas las ciudades y las poblaciones de menor tamaño, hasta el nivel micro regional. En relación con la dinámica poblacional de la zona se analizó el proceso migratorio de inmigración y emigración, con los datos censales manejados y con la información proporcionada por los ayuntamientos de los municipios estudiados. Referente a los planes, programas y políticas de gobierno, se analizó el plan estatal de desarrollo y se complementó con los análisis de los planes municipales de cada uno de los involucrados.

El desarrollo urbano, los procesos de urbanización e inversiones en la materia fueron estudiados con base a los datos proporcionados por gobierno estatal y gobierno municipal; así como generados con los datos de los censos generales de población y vivienda de los años considerados. La población económicamente activa (pea) se estudió con base a los datos arrojados por la clasificación de los sectores económicos de la producción; es decir el porcentaje del total respecto a su respectivo sector primario, secundario y terciario. La población económicamente inactiva en edad de trabajar, como el empleo y desempleo, fueron analizados con base a los indicadores respectivos para ambas ramas de participación-económica. El producto interno bruto estatal con los datos oficiales proporcionados por las respectivas dependencias de gobierno, al igual que el ingreso per cápita en los últimos años considerados.

Una de las características más importantes de la zona de estudio es la importancia de las diversas actividades socio-económicas predominantes en la región, en la que destaca la tasa bruta de actividad económica la cual representa el indicador de la población trabajadora dentro del marco económico territorial de la región; así también la tasa neta de participación; la tasa de ocupación, y la tasa de desocupación de la población económicamente activa la que se refiere al total de personas de 14 años y más en edad de trabajar estén ocupados o desocupados (INEGI, 2005). 


\section{Resultados}

De acuerdo a las proyecciones del Crecimiento Poblacional de INEGI/CONAPO para el periodo 19902030, utilizando los datos estadísticos disponibles hasta 2010 (tabla 3.), se estimó que la población total de Tlaxcala llegaría a 1,287,827 habitantes para el año 2020, lo cual representa un ritmo de crecimiento del $0.96 \%$ anual durante el período 2010 al 2020, sin embargo, al emplear los datos de la Encuesta Intercensal 2015 y del Anuario Estadístico y Geográfico de Tlaxcala de 2016, se observa que para el año 2015, la población está próxima a superar esa cifra, con 1,272,847 habitantes (Figura 3), representando un incremento medio anual del $1.76 \%$ entre 2010 y 2015 dejando entrever con ello, que el panorama a largo plazo que se tenía hace unos años en Tlaxcala, puede no ser tan acertado, y que es posible que, a pesar de los proyectos implementados en el aspecto de salud o planificación familiar, estos no hayan sido suficientes para frenar el crecimiento demográfico, al estar influenciado además, por otras variables socio demográficas como los movimientos migratorios.

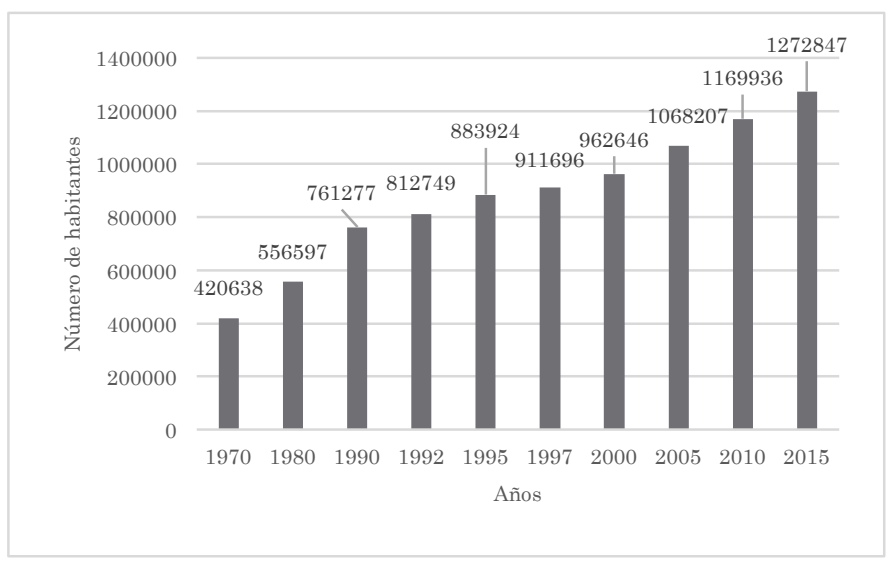

Figura 3. Población Total del Estado de Tlaxcala, 1970-2015

Fuente: INEGI-COESPO, varios censos de población 1970-2010.

Tabla 3.- Población de los municipios del estado de Tlaxcala en el período 1980-2015.

\begin{tabular}{|c|c|c|c|c|c|c|c|}
\hline Clave & Municipios & $\begin{array}{l}\text { Pobl. } \\
1980\end{array}$ & $\begin{array}{l}\text { Pobl. } \\
1990\end{array}$ & $\begin{array}{l}\text { Pobl. } \\
2000\end{array}$ & $\begin{array}{l}\text { Pobl. } \\
2005\end{array}$ & $\begin{array}{l}\text { Pobl. } \\
2010\end{array}$ & $\begin{array}{l}\text { Pobl. } \\
2015\end{array}$ \\
\hline 001 & Amaxac de Guerrero & 4,725 & 6,192 & 7,679 & 7,878 & 9,875 & 11,144 \\
\hline 002 & Apetatitlán de A. Carvajal & 6,072 & 8,990 & 11,795 & 12,268 & 13,361 & 15,271 \\
\hline 003 & Atlangatepec & 3,244 & 4,255 & 5,449 & 5,487 & 6,018 & 6,597 \\
\hline 005 & Apizaco* & 37,894 & 51,744 & 67,675 & 73,097 & 76,492 & 78,624 \\
\hline 009 & Cuaxomulco & 2,649 & 3,365 & 4,255 & 4,340 & 5,066 & 5,272 \\
\hline 010 & Chiautempan & 41,494 & 61,144 & 57,512 & 63,300 & 66,149 & 70,011 \\
\hline 011 & Muñoz de Domingo A. & 2,194 & 3,051 & 4,080 & 4,010 & 4,285 & 4,679 \\
\hline 014 & Hueyotlipan & 8,242 & 11,051 & 12,664 & 12,705 & 13,879 & 14,575 \\
\hline 015 & Ixtacuixtla de M. M. & 20,592 & 30,663 & 30,301 & 32,574 & 35,162 & 38,324 \\
\hline 018 & Contla de J. Cuamatzi & 17,065 & 22,380 & 28,842 & 32,341 & 35,084 & 38,330 \\
\hline 022 & Acuamanala de M. Hgo. & 5,463 & 6,989 & 4,357 & 5,081 & 5,711 & 5,925 \\
\hline 023 & Nativitas & 16,912 & 21,485 & 21,020 & 21,863 & 23,621 & 25,053 \\
\hline 024 & Panotla & 13,763 & 17,903 & 23,391 & 22,368 & 25,128 & 27,154 \\
\hline 026 & Santa Cruz Tlaxcala & 7,912 & 10,522 & 12,824 & 15,193 & 17,968 & 20,242 \\
\hline 028 & Teolocholco & 8,552 & 13,693 & 17,067 & 19,435 & 21,671 & 24,380 \\
\hline 029 & Tepeyanco & 11,311 & 16,942 & 9,006 & 9,176 & 11,048 & 12,047 \\
\hline 031 & Tetla de la Solidaridad & 8,491 & 15,429 & 21,753 & 24,737 & 28,760 & 32,613 \\
\hline 032 & Tetlatlahuca & 12,566 & 15,801 & 10,803 & 11,474 & 12,410 & 13,414 \\
\hline 033 & Tlaxcala* & 35,384 & 50,492 & 73,230 & 83,748 & 89,795 & 95,051 \\
\hline 034 & Tlaxco* & 20,384 & 27,089 & 33,893 & 35,506 & 39,939 & 42,536 \\
\hline 036 & Totolac & 9,041 & 15,200 & 16,682 & 19,606 & 20,625 & 21,814 \\
\hline 038 & Tzompantepec & 8,366 & 10,406 & 9,294 & 12,571 & 14,611 & 16,359 \\
\hline 039 & Xaloztoc & 9,930 & 13,500 & 16,857 & 19,642 & 21,769 & 23,905 \\
\hline 040 & Xaltocan & 7,123 & 8,777 & 7,418 & 8,474 & 9,777 & 10,263 \\
\hline 041 & Papalotla de Xicohténcatl & 12,201 & 17,222 & 22,288 & 24,616 & 26,997 & 30,364 \\
\hline 042 & Xicohtzingo & 7,673 & 8,563 & 10,226 & 10,732 & 12,255 & 13,629 \\
\hline 043 & Yauhquemecan & 8,822 & 12,783 & 21,555 & 27,860 & 33,081 & 38,296 \\
\hline 044 & Zacatelco* & 27,162 & 36,650 & 31,915 & 35,316 & 38,654 & 42,686 \\
\hline 048 & Magdalena Tlaltelulco, La & - & - & 13,697 & 15,046 & 16,834 & 18,873 \\
\hline 049 & San Damián Texoloc & - & - & 4,360 & 4,480 & 5,064 & 5,569 \\
\hline
\end{tabular}




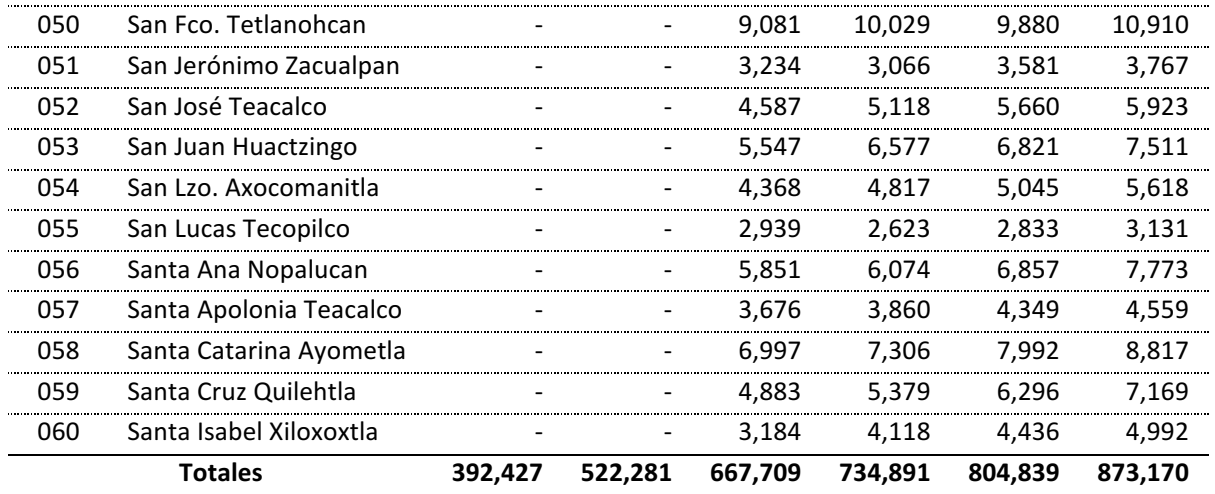

Fuente: Elaborada por los autores con los datos de diferentes Censos y Conteos de Población y Vivienda de Tlaxcala, (INEGI, 1980, 1990, 2000, 2005, 2015).

Por lo que respecta al nivel de desarrollo socioeconómico municipal y regional, se muestran claras diferencias. Como se ha mencionado previamente, uno de los principales indicadores al cual se asocian factores sinérgicos que dinamizan las regiones, es el Grado de Urbanización, en una primera aproximación y tomando como referencia el periodo de 1970-2000, se observa que en el primer año la población rural representaba el $66.68 \%$ de la población estatal, mientras que la población urbana sólo representaba el $13.08 \%$, el resto era población mixta, es decir, la que se encontraba en transición de población rural a población urbana; para el año 2000 se puede distinguir que hubo un incremento en la población urbana representando el 38.59\%, para el año 2005 el grado de urbanización aumentó a 39.97\%; y cinco años después, se observa una gran transición de la población rural a urbana, llegando a un grado de urbanización 79.35\%, finalmente para el año 2015, se llega al $79.87 \%$, y se aprecia una desaceleración en el grado de urbanización (Figura 4).

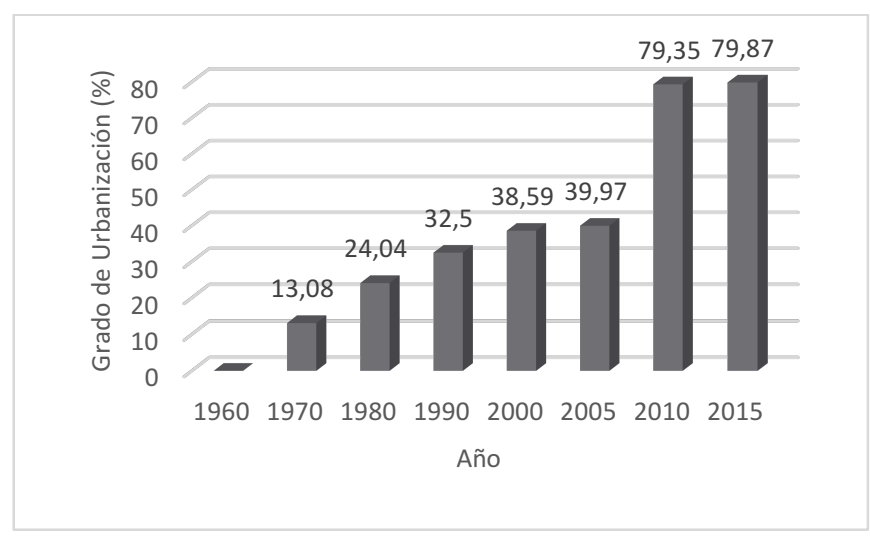

Figura 4. Grado de urbanización del Estado de Tlaxcala, 1970-2005. Fuente: Elaboración propia con datos del Sistema de Ciudades y Desarrollo Regional en el estado de Tlaxcala, 2004. Actualizado con datos del Censo de Población y Vivienda, INEGI, 2010 \& Anuario Estadístico y Geográfico de Tlaxcala, 2016 (INEGI, 2010, 2017a).
El incremento en la participación porcentual de la población urbana se debe a varios factores: no sólo está determinado por el crecimiento natural y migratorio, sino también por el aumento de la población de aquellas localidades que en determinado momento alcanzaron la categoría de urbanas, debido entre otros aspectos, a la acelerada industrialización que la entidad ha mostrado en esos años y a la creciente participación del sector terciario en la economía local.

Cuando se habla de ciudades, se entiende que son aquellas localidades con 15 mil y más habitantes; el grado de urbanización es el porcentaje de la población urbana respecto a la total; y la tasa de urbanización es el incremento medio anual del grado de urbanización.

Tomando como base estos criterios y de acuerdo con los datos censales del año 2000, hasta ese año se tenían identificadas un total de 10 localidades urbanas en todo el estado, dentro de las que destaca la localidad de Tlaxcala con un grado de urbanización del $99.98 \%$ y la localidad de Zacatelco con un grado de urbanización del 99.33\%; es decir, prácticamente toda la población de estas dos localidades es urbana (Tabla 4). 
Tabla 4.- Grado de urbanización de localidades mayores a 15,000 habitantes, Tlaxcala; 2000-2010.

\begin{tabular}{|c|c|c|c|c|c|c|c|c|c|}
\hline \multirow{2}{*}{$\begin{array}{l}\text { Localidades } \\
\text { Categorías }\end{array}$} & \multicolumn{3}{|c|}{ Año 2000} & \multicolumn{3}{|c|}{ Año 2005} & \multicolumn{3}{|c|}{ Año 2010} \\
\hline & $\begin{array}{l}\text { Pobl. } \\
\text { Mpal }\end{array}$ & $\begin{array}{c}\text { Loc }>15000 \\
\text { hab }\end{array}$ & $\begin{array}{c}\text { Grado } \\
\text { Urb. (\%) }\end{array}$ & $\begin{array}{l}\text { Pobl. } \\
\text { Mpal }\end{array}$ & $\begin{array}{c}\text { Loc }>15000 \\
\text { Hab }\end{array}$ & $\begin{array}{c}\text { Grado } \\
\text { Urb. (\%) }\end{array}$ & $\begin{array}{l}\text { Pobl. } \\
\text { Mpal }\end{array}$ & $\begin{array}{c}\text { Loc }>15000 \\
\text { hab }\end{array}$ & $\begin{array}{c}\text { Grado } \\
\text { Urb. (\%) }\end{array}$ \\
\hline Apizaco & 67,675 & 48,049 & 71.00 & 73,097 & 49,459 & 67.66 & 76,492 & 49506 & 64.72 \\
\hline Calpulalpan & 37,169 & 27,451 & 73.85 & 40,790 & 30,004 & 73.56 & 44,807 & 33263 & 74.24 \\
\hline Contla & 28,842 & 22,646 & 78.52 & 32,341 & 25,456 & 78.71 & 35,084 & 27610 & 78.70 \\
\hline Chiautempan & 57,512 & 44,561 & 77.48 & 63,300 & 46,776 & 73.90 & 66,149 & 48030 & 72.61 \\
\hline Huamantla & 66,561 & 40,854 & 61.38 & 77,076 & 47,286 & 61.35 & 84,979 & 51996 & 61.19 \\
\hline Papalotla & 22,288 & 19,135 & 85.85 & 24,616 & 20,967 & 85.18 & 26,997 & 22969 & 85.08 \\
\hline Villa Vicente $\mathrm{G}$ & 54,387 & 47,804 & 87.9 & 64,107 & 55,760 & 86.98 & 69,615 & 60001 & 86.19 \\
\hline Tlaxcala & 73,230 & 73,213 & 99.98 & 83,748 & 83,737 & 99.99 & 89,795 & 89,795 & 100 \\
\hline Xaloztoc & 16,857 & 16,098 & 95.5 & 19,642 & 17,416 & 88.67 & 21,769 & 21,769 & 100 \\
\hline Zacatelco & 31,915 & 31,700 & 99.33 & 35,316 & 35,036 & 99.21 & 38,654 & 38466 & 99.51 \\
\hline La Magdalena T & $s / d$ & $s / d$ & $s / d$ & 15,046 & 15,046 & 100 & 16,834 & 16834 & 100 \\
\hline Tetla de la Solidaridad & - & - & - & - & - & - & 28760 & 15,161 & 53.72 \\
\hline TOTAL & 456,436 & 371,511 & 81.39 & 529,079 & 426,943 & 80.70 & 599,935 & 475,400 & 79.24 \\
\hline
\end{tabular}

Fuente: Datos de los Conteos y Censos de Población y Vivienda, y la Encuesta Intercensal 2015. (INEGI, 2000, 2005, 2015).

Para el año 2005 aumentó una localidad (La Magdalena Tlaltelulco) a la categoría de ciudad bajo la caracterización anterior y con un grado de urbanización del 100\% en el año 2010 la Localidad de Tetla, también alcanzó la categoría de ciudad con una población de 15161 habitantes, aun cuando el grado de urbanización en el municipio es del $53.72 \%$, con lo que es la localidad de menor grado de urbanización, al analizar el grado de urbanización alcanzado con datos poblacionales del II Conteo de Población y Vivienda 2005, si bien se observaron fluctuaciones, se debió a las diferentes proporciones de aumento de la población total que se dio en las diferentes localidades y municipios, puesto que la población urbana mostró un aumento importante.

En conjunto, 10 localidades mostraron altas tasas de crecimiento de su población urbana en las décadas 70-80 y $80-90$ del $9.3 \%$ y $7.2 \%$, respectivamente; precisamente en los periodos de mayor crecimiento y despegue de la economía local; las localidades con más de 15,000 habitantes y con mayor tasa de crecimiento poblacional en el período 2005-2010 son: La Magdalena Tlatelulco, Calpulalpan, Huamantla, Zacatelco y Papalotla que van desde el $10.62 \%$ al $8.72 \%$ respectivamente. (Figura 5)

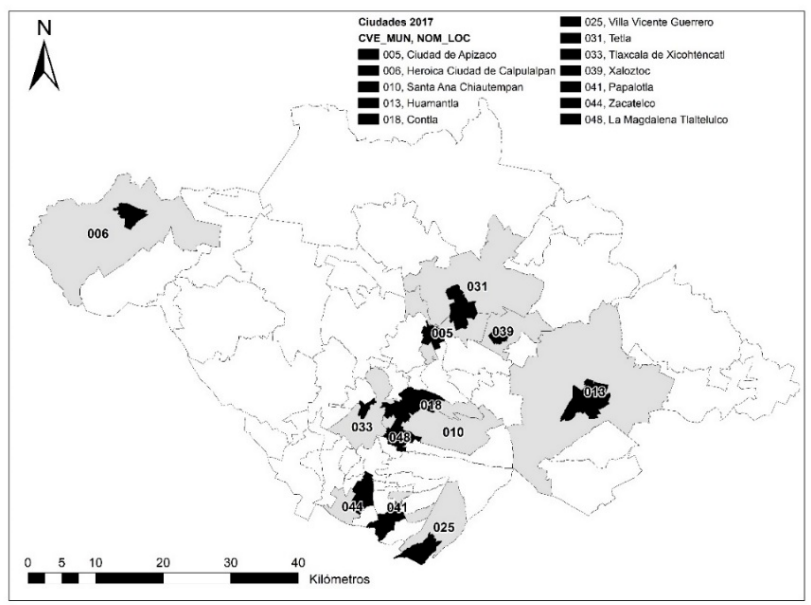

Figura 5. Mapa de las localidades más pobladas del estado de Tlaxcala.

Fuente: Elaboración propia con los datos cartográficos del Marco geoestadístico, 2017. (INEGI, 2017b)

En este proceso, la localidad de Tlaxcala es la que creció a un mayor ritmo, pues en la década 80-90 logró una tasa del $10.6 \%$ que fue mayor al promedio estatal, y aunque para la última década bajó al 3.8\%, siguió siendo superior al de las demás localidades.

Por su parte, las localidades de Apizaco y Zacatelco registraron en la década 90-00 las tasas de urbanización más bajas, esto es del $1.0 \%$ y del $0.4 \%$, respectivamente; también se puede observar que es precisamente la región de Huamantla la que tiene el menor grado de 
urbanización y que se ve reflejada en la evolución de la jerarquía de las localidades urbanas principales de Tlaxcala, para 2005-2010 la jerarquización ha cambiado con respecto a las localidades teniendo en los primero lugares a Tlaxcala, y en los últimos a la localidad de La Magdalena (Tabla 5).

Tabla 5.- Evolución de la jerarquía de las localidades urbanas principales de Tlaxcala, 1970-2010.

\begin{tabular}{|c|c|c|c|c|c|c|}
\hline Rango ciudad & 1970 & 1980 & 1990 & 2000 & 2005 & 2010 \\
\hline 01 & Apizaco & Apizaco & Tlaxcala de $X$ & Tlaxcala de $X$ & Tlaxcala de $\mathrm{X}$ & Tlaxcala de $X$ \\
\hline 02 & Villa V. Gro. & Villa V. Gro. & Apizaco & Apizaco & Villa V. Gro & Villa V. Gro \\
\hline 03 & Huamantla & Huamantla & Villa V. Gro. & Villa V. Gro. & Apizaco & Huamantla \\
\hline 04 & - & Zacatelco & Chiautempan & Chiautempan & Huamantla & Apizaco \\
\hline 05 & - & Tlaxcala de X. & Huamantla & Huamantla & Chiautempan & Chiautempan \\
\hline 06 & - & Calpulalpan & Zacatelco & Zacatelco & Zacatelco & Zacatelco \\
\hline 07 & - & - & Calpulalpan & Calpulalpan & Calpulalpan & Calpulalpan \\
\hline 08 & - & - & Contla & Contla de J.C. & Contla de J.C. & Contla de J.C \\
\hline 09 & - & - & - & Papalotla de X & Papalotla de X. & Papalotla de X. \\
\hline 10 & - & - & - & Xaloztoc & Xaloztoc & Xaloztoc \\
\hline 11 & - & - & - & - & La Magdalena Tla. & La Magdalena Tla. \\
\hline 12 & - & - & - & - & - & Tetla \\
\hline
\end{tabular}

Nota: Los cuadros en blanco indican que no había población urbana en esos años.

Fuente: INEGI; Censos de población y vivienda, varios años.

En el año 2000, el estado de Tlaxcala contaba con un total de 193,288 viviendas particulares habitadas, para 2015 esta cifra fue superada en $60.64 \%$, es decir que surgieron 117,216 nuevas viviendas de las registradas 15 años atrás, lo que implica una tasa de crecimiento medio anual de 3.79\%. Durante este período entre el 33.3 y $32.97 \%$ se concentraron en Tlaxcala, Apizaco, Huamantla,
Chiautempan y San Pablo del Monte. En cuanto a las viviendas urbanas y rurales de la región durante el año 2005 (Tabla 6), los datos registraron 164,350 viviendas que significaban el $70.27 \%$ del total estatal, en tanto que el resto del estado indicaba un total de 69,531 viviendas, es decir el $29.73 \%$ del total estatal.

Tabla 6.-Comparativo quinquenal de viviendas particulares habitadas en la zona de estudio de Tlaxcala y los 5 municipios con mayor población (Tlaxco, Apizaco, Tlaxcala, Zacatelco y Huamantla) 2000-2015, México.

\begin{tabular}{|c|c|c|c|c|c|c|}
\hline Unidad & $\begin{array}{l}\text { Año } \\
2000\end{array}$ & $\begin{array}{l}\text { Año } \\
2005\end{array}$ & $\begin{array}{l}\text { Año } \\
2010\end{array}$ & $\begin{array}{l}\text { Año } \\
2015\end{array}$ & Incremento 2000-2015 & T.C.A \\
\hline Viviendas Particulares & 193,288 & 233,881 & 274,202 & 310,504 & 117,216 & $3.79 \%$ \\
\hline Cinco Municipios & 61,503 & 79,726 & 91844 & 102370 & 40,867 & $4.15 \%$ \\
\hline Resto Municipios & 132,889 & 154,128 & 182,358 & 208,134 & 76,349 & $3.59 \%$ \\
\hline
\end{tabular}

Fuente: Elaborado por los autores del trabajo con base en los censos de población de los años considerados.

Los ocupantes registrados de la región representaron 736,517 ocupantes que significaban el $69.05 \%$ del total estatal, y los 19 municipios restantes registraron 330,065 ocupantes que representaron el $30.95 \%$ del total. El promedio de ocupantes por vivienda descendió de 4.9 a 4.6 en el periodo considerado. Los municipios que más destacan porque más del $84 \%$ de sus viviendas cuentan con 3 o más cuartos son Tlaxcala y Apizaco.
El desarrollo regional urbano de México, en su diagnóstico e implicaciones futuras, y en relación con esta investigación, describe al proceso de urbanización desde el punto de vista del incremento demográfico, la concentración poblacional y su consecuente proceso de transformación territorial, tal como el aumento de aglomeración en las localidades involucradas; principalmente Tlaxcala y zona de influencia ApizacoTlaxco. 
Ahora bien, el proceso de urbanización en tanto sistema de ciudades megapolitana y la metropolización, por la cual es alcanzada la región motivo de esta investigación, engloban entre otras jerarquías para su estudio a los postulados que planteó Ramírez (1996), en el que destaca su diferenciación social-territorial; y la aproximación que hace acerca del análisis regional desde la teoría, como aparece en la tabla 7.

Tabla 7

Análisis regional desde la teoría; una aproximación

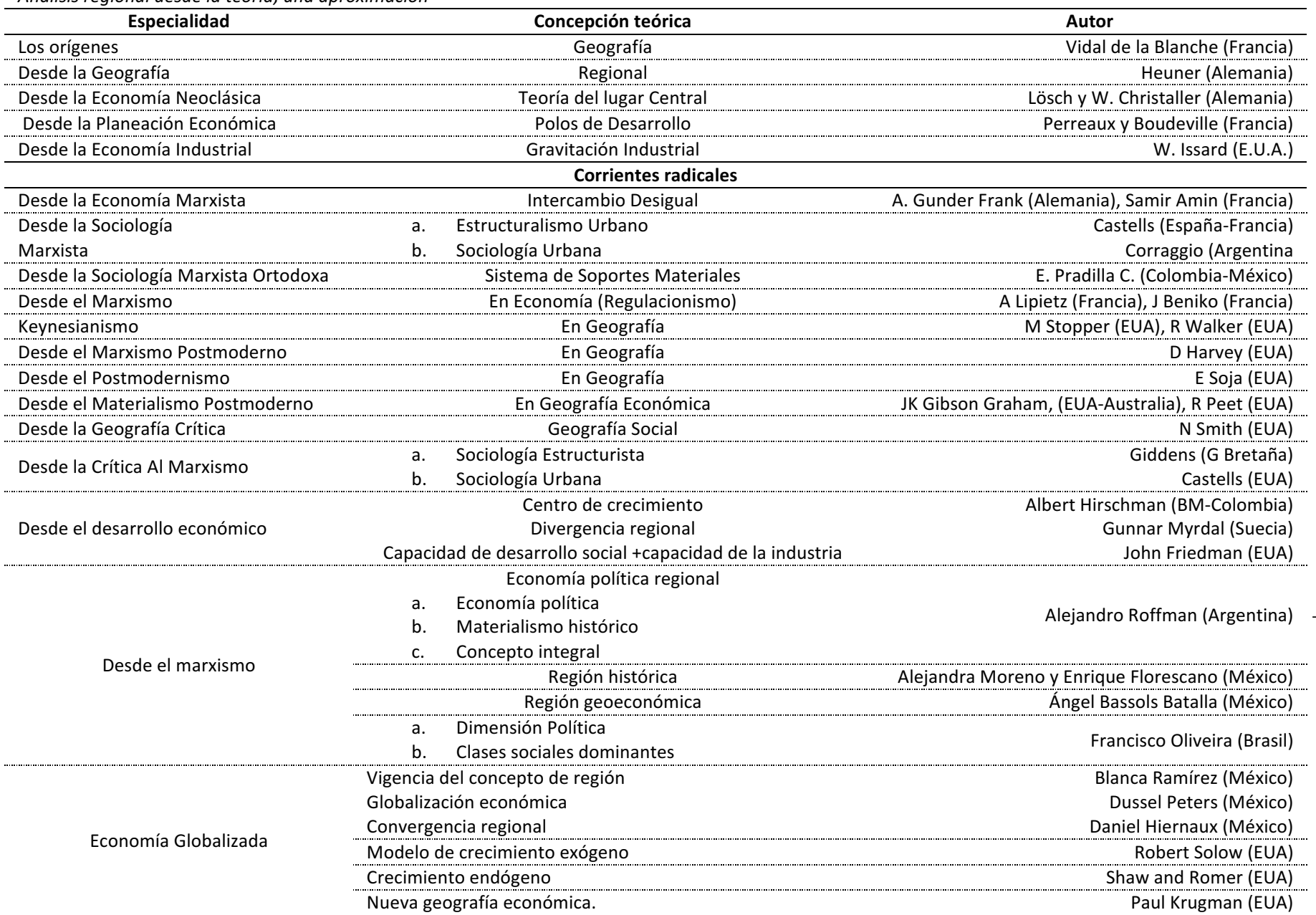

Fuente: Interpretación gráfica resumida y actualizada de las posiciones planteadas en Los paradigmas contemporáneos en el análisis de la relación Territorio-Sociedad en Diseño y Sociedad de Ramírez (1996), citado en Reynoso et al. (2011) y complementada por los autores en este trabajo con Román (2002).

La necesidad de explicar las diferencias económicas en un territorio y las políticas que se deben contemplar para superarlas, han originado diversas teorías acerca del análisis y desarrollo regional que corresponden, por un lado, a cada uno de los momentos históricos y, por otro, a las inclinaciones ideológicas de sus autores, (Román, 2002).

Desde esta perspectiva, para el análisis regional no se contempló una uniformidad metodológica, dado que el concepto de región tiene innumerables connotaciones de acuerdo con cada especialista geógrafos, historiadores, economistas, antropólogos, etc., (ver Tabla 7), pero se puede afirmar que la región es una realidad cambiante, porque a lo largo del tiempo cambia la sociedad ahí asentada (Román, 2002).

De acuerdo con lo anterior, las poblaciones de los municipios considerados desempeñan un importante rol gravitatorio interno y externo de la región, funcionando como polos de atracción (Hernández, 2008) en cuanto a mano de obra barata. La mayor concentración de 
habitantes se ubica en las regiones Sur (Zacatelco), Centro Sur (Tlaxcala) y Centro Norte (Apizaco). La localización y distribución de las localidades se extiende desde el flanco sur, siendo esta una extensión de la ciudad de Puebla, la cual se encuentra conurbada con los poblados de Villa Vicente Guerrero, Tenancingo y Xicohtzinco, todos pertenecientes al Estado de Tlaxcala (Figura 6).

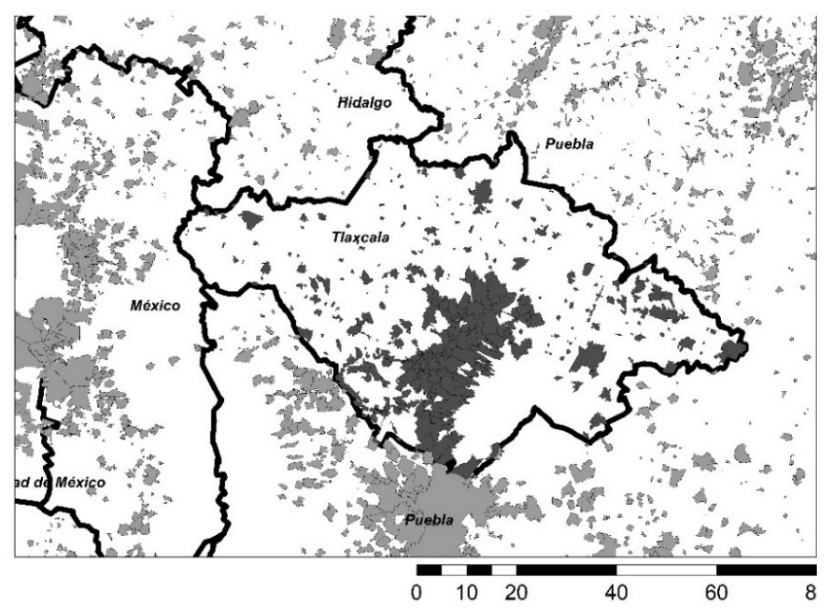

Figura 6. Mancha urbana de Tlaxcala y sus estados colindantes.

Fuente: Elaboración propia a partir de los datos del Marco Geoestadístico Nacional 2017 (INEGI, 2017b).

La mayor aglomeración de zonas urbanas y, por consiguiente, de habitantes tiene un comportamiento particular: la expansión de la mancha urbana se ha dado en sentido de norte a sur y hasta ahora ha sido menor la expansión de este a oeste. En el Estado de Tlaxcala, en tanto, se observan los tres patrones espaciales de expansión urbana (Hernández y Gutiérrez, 2010), se aprecia que las principales ciudades del estado presentan un patrón de expansión continuo concéntrico, mientras que las localidades próximas a las ciudades experimentan una expansión tentaculada o lineal y se observa, en menor grado, la expansión fraccionada en las localidades periféricas del estado. Respecto de la población rural esta se distribuye a lo largo del estado en sus 1.382 localidades, gravitando en torno al corredor central donde se localizan las ciudades de Tlaxco, Apizaco, Tlaxcala y Zacatelco (Figura 7).

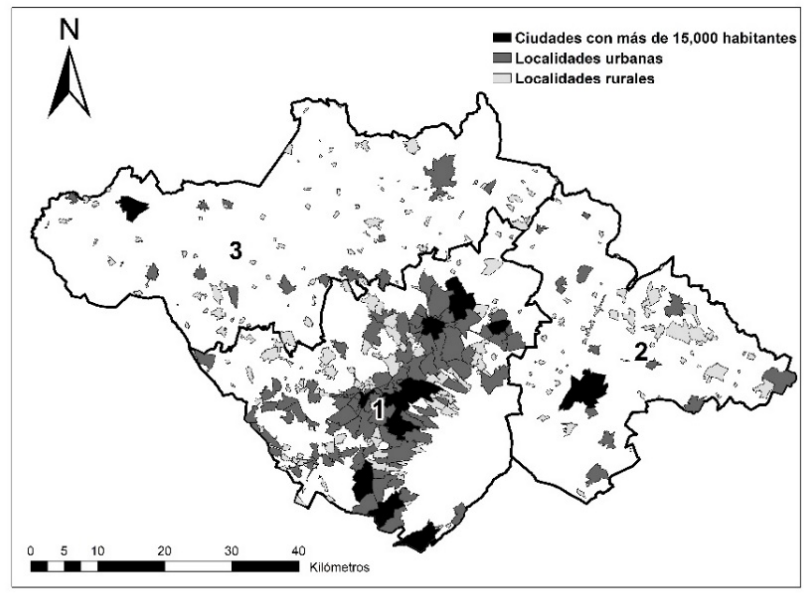

Figura 7. Polígonos urbanos y ciudades del Estado de Tlaxcala, 2017. Fuente: Elaboración propia a partir de Cartografía Geoestadística de INEGI (INEGI, 2017b).

Tomando como referencia la Encuesta Intercensal 2015 del INEGI, tenemos que la población total del Estado de Tlaxcala alcanza los 1.272.847 habitantes, de los cuales los cinco municipios más poblados son Tlaxcala con 95.051 habitantes; Huamantla con 92.887 habitantes; Apizaco con 78.624 habitantes; San Pablo del Monte con 77.242 habitantes; y Chiautempan con 70.011 habitantes.

En general, de un total de 473.673 el Estado de Tlaxcala tiene una población ocupada de $11,61 \%$ en el sector primario, $34,29 \%$ en el sector secundario, $16,63 \%$ en el comercio, $36,17 \%$ en servicios y $1,34 \%$ no especificado. Así mismo, de los cinco municipios Tlaxcala tiene una población ocupada de 40.810, siendo la principal actividad económica con $63,24 \%$ en servicios, Huamantla con 32.116 de población ocupada con el $35,86 \%$ en el sector secundario, Apizaco con 31.870 población ocupada con $44,69 \%$ en el sector servicios, San Pablo del Monte con 30.565 de población ocupada con el $53,22 \%$ en el sector secundario y Chiautempan con 28.211 de población ocupada con el $41,05 \%$ en el sector servicios.

Al respecto, Brambila (2002) menciona la importancia de los indicadores para el análisis regional, así como Aguilar, Graizbord y Sánchez (1998) hace lo propio en torno a la actividad productiva en el orden de importancia por su aportación al PIB, considerando el análisis de los indicadores de empleo y desempleo como un referente para el cálculo del grado de urbanización y el nivel de desarrollo urbano. 
A partir de la Encueta Nacional de Ocupación y Empleo del INEGI al cuarto trimestre de 2016, se tiene que la población económicamente activa (PEA) es de 580.978; la población económicamente inactiva (PEI) es de 352.592; la población ocupada es de 560.154; y desocupada es de 20.824 .

Tlaxcala reportó 560 mil trabajadores en 2016, principalmente en la industria manufacturera con 141.962 personas; comercio con 96.263 personas; seguido de agricultura, ganadería, silvicultura, caza y pesca con 70.837 personas.

El Producto Interno Bruto (PIB) del estado fue superior a los 104 mil millones de pesos en 2015, con lo que aportó $0,6 \%$ al PIB nacional. Las actividades terciarias donde se encuentran el comercio y servicios inmobiliarios, por su parte, aportaron $62 \%$ al PIB estatal en 2015 , en tanto que las actividades secundarias lo hicieron con un $35 \%$ y las actividades primarias con un $3 \%$.

Así mismo, la tasa global de fecundidad en el Estado de Tlaxcala en promedio es de 2,26 y en los municipios con un rango de 50.000 a 99.999 habitantes, donde entran los cinco más poblados del estado, con una tasa de 2,37 .

La marginación en el Estado de Tlaxcala contempla que de la población de 5 años y más sobre un total de 1.157.531, el 96,85\% reside en el mismo municipio, del $3,12 \%$ al $3.60 \%$ en otro municipio o en otra entidad o país. Respecto de los estados receptores se destacan: Puebla, Estado de México y la Ciudad de México, en tato que entre los países receptores se cuentan Estados Unidos y Canadá.

\section{Conclusiones}

El estudio determinó que el crecimiento poblacional presentado en el Estado de Tlaxcala se dio de tres formas, el patrón de expansión continuo concéntrico, expansión tentaculada o lineal, expansión fraccionada en las localidades periféricas del estado, mediante puntos de concentración poblacional históricamente determinados por las relaciones sociales de producción con los estados colindantes, concluyendo que la ocupación social del espacio mantiene una relación estrecha con el producto interno bruto. No es posible analizar la ocupación social deslindándola de la economía del estado.

Los asentamientos humanos, por su lado, se han manifestado principalmente en la parte central del estado, presentando una dependencia centro-periferia respecto de las principales ciudades, por lo que la expansión de la mancha urbana se ha dado en la zona central del norte al sur del estado, particularmente donde colinda con el Estado de Puebla, la zona más urbanizada de este estado.

Por otra parte, se determinó que, al no presentarse una desaceleración tan pronunciada en el crecimiento demográfico, ahora más que nunca, es necesario implementar la visión de desarrollo regional del POTDUT 2013, en los Planes de Desarrollo Municipal y Programas Municipales de Desarrollo Urbano de las cabeceras regionales.

La urbanización del Estado de Tlaxcala repercute en el crecimiento de la población urbana y la disminución de la población rural y sus actividades, así como el cambio de uso de suelo, el cual impacta directamente en el sector ambiental, en la pérdida de ecosistemas, áreas verdes, bosques etc.; en tanto que los asentamientos urbanos irregulares invaden áreas verdes lo que se debe al incumplimiento de los ordenamientos elaborados para el Estado de Tlaxcala, la nula supervisión en su seguimiento, pero sobre todo a la cuota política que se maneja cuando hay elecciones estatales, la compra de votos en donde el sector ambiental en la parte del territorio se vuelve la moneda de cambio para el beneficio electoral y económico de algunos sectores.

\section{Recomendaciones}

Resulta necesario replantear la regionalización del Estado de Tlaxcala para establecer, apropiadamente, los proyectos encaminados al desarrollo social, económico y ambiental de la región, pues resulta fundamental integrar esta visión de desarrollo regional en los Planes de Desarrollo Rural y los Programas de Ordenamiento Territorial de las regiones.

Es una necesidad urgente replantear las políticas y estrategias en función del contexto estatal y regional. Enfocándolas no solo a la competitividad y la generación de empleo, sino también a fomentar una movilidad sustentable, mejorar el control de uso de suelo y 
desarrollo, gestión articulada para el desarrollo de proyectos y mejoramiento de las regiones, para finalmente, mejorar la calidad de vida de sus habitantes y lograr un desarrollo sustentable.

Un trabajo pendiente es realizar el estudio del impacto del sector económico en el sector ambiental; dentro de las teorías de análisis regional sería importante incluir el análisis regional sobre la base del análisis ambiental, particularmente con las repercusiones que trae el fenómeno del cambio climático en lo que respecta a la reordenación del territorio, infraestructura, reubicación de ciudades, cambio de condiciones en la producción agropecuaria, dieta, control de nuevas enfermedades, establecimiento de unidades médicas y su acceso, escuelas, asentamientos urbanos y rurales,

\section{Referencias}

Aguilar, A., Graizbord, B. y Sánchez, C. (1998). Las ciudades intermedias y el desarrollo regional en México (1a Edición). México DF: Conaculta, Universidad Nacional Autónoma de México, Colmex.

Aguilar, A. (2004). Procesos metropolitanos y grandes ciudades: dinámicas recientes en México y otros países. México DF: Cámara de Diputados-LIX Legislatura, Universidad Nacional Autónoma de México, Consejo Nacional de Ciencia y Tecnología, Miguel Ángel Porrúa.

Bachelard, G. (2000). La poética del espacio. Recuperado de

https://monoskop.org/images/1/16/Bachelard_Gasto n_La_poetica_del_espacio.pdf

Bazant, J. (2001). Lineamientos para el ordenamiento territorial de las periferias urbanas de la ciudad de México. Papeles de población, 7(27), 223-239. Recuperado de

http://www.scielo.org.mx/scielo.php?script=sci_artte $\underline{x t \& p i d=S 1405-74252001000100010 \& \operatorname{lng}=e s \& t \operatorname{lng}=e s}$

Brambila, P. (2002). Expansión urbana en México (1a Edición). México DF: El Colegio de México. etc. Desde esta perspectiva, quizás sea necesario pasar desde un estudio de la ocupación social del espacio basado en la actividad económica al estudio de la ocupación social del espacio con base en las consideraciones ambientales que impone el cambio climático.

La supervisión en el cumplimiento de los ordenamientos territoriales basado en la comunidad, en la sociedad y no en gobiernos estatales sexenales o en necesidades electorales se hace necesario. Deslindar los colores de los gobiernos (partidos políticos) para el manejo de los presupuestos de los estados y municipios es una tarea pendiente que se debe de regular para la priorización de las acciones que el estado requiere [B]

de Mattos, C. (2002). Transformación de las ciudades latinoamericanas: ¿impactos de la globalización? EURE (Santiago), 28(85), 5-10.

https://dx.doi.org/10.4067/S025071612002008500001

Di Virgilio, M., Guevara, T., \& Arqueros, Ma. (2014). Un análisis comparado sobre la implementación de políticas de regularización de asentamientos informales en Argentina, Brasil y México. Revista INVI, 29(80), 17-51.

Garza, G. (2007). La urbanización metropolitana en México: normatividad y características socioeconómicas. Papeles de población, 13(52), 77 108. Recuperado de http://www.scielo.org.mx/scielo.php?script=sci_artte xt\&pid=S1405-74252007000200004\&Ing=es\&tlng=pt

Guillén, R. (2004). Revisitando la teoría del desarrollo bajo la globalización. Economía UNAM, 1(1), 19-42. Recuperado de

http://www.scielo.org.mx/scielo.php?script=sci_artte xt\&pid=S1665-952X2004000100003\&Ing=es\&tIng=es

Gutiérrez, J. (2013). La planeación urbana en México: retos y perspectivas desde la agenda internacional. Revista de Urbanismo, 29, 2-16. https://doi.org/10.5354/0717-5051.2013.30137 
Gutiérrez, J. (2017). México y la nueva agenda urbana. Hoja de ruta con trazos invisibles. [en] capacidades institucionales en el estado de México. Bitácora Urbano Territorial, 27(2), 35-43. https://doi.org/10.15446/bitacora.v27n2.63133

Harvey, D. (2007). Breve historia del neoliberalismo. Madrid: Ediciones Akal.

Hernández, H. (2008). Procesos de urbanización y calidad de vida en las regiones a de Apizaco y Tlaxcala (1 $\underline{a}$ Edición). México DF: El Colegio de Tlaxcala.

Hernández, J. y Gutiérrez, M. (2010). Patrones espaciales de expansión urbana de Santiago de Chile, período 1975-2003. Revista de Urbanismo, 22, 92-106. http://dx.doi.org/10.5354/0717-5051.2010.8792

Instituto Nacional de Estadística y Geografía, INEGI. (1980). X Censo General de Población y Vivienda. México DF: Autor.

Instituto Nacional de Estadística y Geografía, INEGI. (1990). XI Censo General de Población y Vivienda. México DF: Autor.

Instituto Nacional de Estadística y Geografía, INEGI. (2000). XII Censo General de Población y Vivienda 2000. México DF: Autor.

Instituto Nacional de Estadística y Geografía, INEGI. (2005). II Conteo de Población y Vivienda 2000-2005 de Tlaxcala. México DF: Autor.

Instituto Nacional de Estadística y Geografía, INEGI. (2010). Censo de Población y Vivienda 2010. México DF: Autor.

Instituto Nacional de Estadística y Geografía, INEGI. (2015). Encuesta Intercensal 2015. México DF: Autor.

Instituto Nacional de Estadística y Geografía, INEGI. (2016). Encuesta Nacional de Ocupación y Empleo. México DF: Autor.

Instituto Nacional de Estadística y Geografía, INEGI. (2017a). Anuario Estadístico de Tlaxcala 2016. México DF: Autor.

Instituto Nacional de Estadística y Geografía, INEGI. (2017b). Marco Geoestadístico Nacional, junio 2017. México.
Lattuada, M. (2002). El peronismo y los sectores sociales agrarios: la resignificación del discurso como articulador de los cambios en las relaciones de dominación y la permanencia de las relaciones de producción. Mundo agrario, 3(5). Recuperado de http://www.scielo.org.ar/scielo.php?script=sci_arttex t\&pid=S1515-59942002000200002\&lng=es\&tlng=en.

Le Corbusier (1990). Carta de Atenas. México DF: Editorial Ariel.

Lipietz, A. (1979). El capital y su espacio. México DF: Editorial Siglo XXI.

Navarrete, D. (2013). Formas y conceptos de la urbanización planetaria para una lectura de la ciudad latinoamericana. Andamios, 10(22), 69-90. Recuperado de

http://www.scielo.org.mx/scielo.php?script=sci_artte xt\&pid=S1870-00632013000200005\&lng=es\&tlng=es.

Peñalver, L. (2000). Pensar en lo urbano: teorías, mitos y movimientos. Mérida: Universidad de los Andes, Fondo Editorial CRáTERA.

Quiroz, H. (2013). Elementos para una teoría de la ciudad mexicana contemporánea desde la práctica urbanística. Andamios, 10(22), 113-128. Recuperado de

http://www.scielo.org.mx/scielo.php?script=sci_artte xt\&pid=S1870-00632013000200007\&lng=es\&tlng=es.

Ramírez, H. (2008). Desarrollo, subdesarrollo y teorías del desarrollo en la perspectiva de la geografía crítica. Revista Escuela de Historia, 7(2). Recuperado de http://www.scielo.org.ar/scielo.php?script=sci_arttex t\&pid=S1669-90412008000200005\&lng=es\&tlng=es

Ramírez, B. (1996). Los paradigmas contemporáneos en el análisis de la relación territorio-sociedad en diseño y sociedad, México. Revista de Teoría y Análisis del Diseño, 62-73.

Reynoso, R., Carrasco, R., Calderón, H., y Cardona, M. (2012). La ocupación social del espacio estrategia del capital en la planeación del territorio municipal Tlaxco, Tlaxcala. Mundo Siglo XXI, 7(27), 79-87. Recuperado de http://132.248.9.34/hevila/MundosigloXXI/2012/no2 7/6.pdf 
Reynoso, R., Martínez, M., y Alvarado, M. (2011). La ocupación social del espacio, región metropolitana de la cuenca del río Zahuapan "Tlaxco, Apizaco, Tlaxcala y Zacatelco", Estado de Tlaxcala México. Recuperado de

http://revistasum.umanizales.edu.co/ojs/index.php/A suntosecoyadmon/article/view/2186

Román Alarcón, R. (2002). La región y su análisis: teorías para su estudio. Clío 2002, Nueva Época, 1(28). Recuperado de http://historia.uasnet.mx/rev_clio/Revista_clio/Revist a28/11_RegionyAnalisis.TeoriasdeEst_RigobertoRoma $\underline{\text { n.pdf }}$
Sobrino, J. (2012). La urbanización en el México contemporáneo. Recuperado de https://www.cepal.org/sites/default/files/events/files /jaime_sobrino.pdf

Ugalde, V. (2010). La coordinación institucional del ordenamiento territorial en México. Revista de Geografía Norte Grande, 47, 105-120.

https://dx.doi.org/10.4067/S0718-

34022010000300006 